\title{
Examining Demographic Factors Related to Cigarette Smoking among Undergraduate Students at a Turkish University
}

\author{
Erkan Oktay ${ }^{1}$, Ali Kemal Çelik ${ }^{2} \&$ Ahmet İlker Akbaba ${ }^{2}$ \\ ${ }^{1}$ Department of Econometrics, Atatürk University, Erzurum, Turkey \\ ${ }^{2}$ Department of Business Administration, Atatürk University, Erzurum, Turkey \\ Correspondence: Ali Kemal Çelik, Faculty of Economics and Administrative Sciences, Department of Business \\ Administration, Atatürk University, Erzurum, 25240, Turkey. Tel: 90-442-231-2099. E-mail: \\ akemal.celik@atauni.edu.tr
}

Received: April 29, 2013

Accepted: May 12, 2013

Online Published: May 13, 2013

doi:10.5430/ijhe.v2n2p175

URL: http://dx.doi.org/10.5430/ijhe.v2n2p175

This paper is a revised and extended version of the conference paper presented at the "13th International Conference on Econometrics, Operations Research and Statistics,” on 24-26 May 2012, Famagusta, Cyprus.

\begin{abstract}
Cigarette smoking is the leading global preventable health risk, and it is associated with well-known health risks such as morbidity, mortality, cancer, cardiovascular disease, and nicotine addiction. When analyzed by age group, cigarette smoking in Turkey is the most prevalent among younger adult populations. The college years appear to be a time of increased risk for smoking initiation and movement into regular patterns of use, although college smokers are more likely to be non-daily smokers, meaning that they smoke more in social situations. This paper aims to identify the demographic factors related to cigarette smoking of undergraduate students in Erzurum, Atatürk University; to interpret these factors, and to assist in informing alternatives for taking more effective action than the typical cessation campaigns. Using logistic regression analysis with cross-sectional data obtained using the questionnaire; the factors affecting cigarette smoking in this context were identified. There were significant effects for the demographic factors including gender, geographical region, parents' residence, father's profession, family members, occupation status, and general satisfaction, $p<.05$; faculty and present residence, $p<.10$. The survey and logistic regression results of this paper also showed marked similarities with recent studies in the reviewed literature and recent policies.
\end{abstract}

Keywords: Cigarette smoking, Undergraduate students, Demographic factors, Logistic regression, Turkey

\section{Introduction}

Tobacco use has been identified as one of the four behavioral risk factors that feature as pervasive aspects of economic transition, rapid urbanization, and twenty-first century lifestyles, and the greatest effects of these risk factors fall incrementally on underdeveloped and emerging countries (World Health Organization [WHO], 2011). Estimation results suggest that by 2020, seven of every ten people will be killed by tobacco-related diseases in the developing world (The World Bank, 1999; Maziak et al., 2004). As the 2012 World Health Organization Global Report points out, tobacco is the only legal drug that kills many of its users; direct tobacco smoking is currently responsible for about five million deaths across the world each year (one death every six seconds), and an additional six thousand people are estimated to die from the effects of second-hand smoke (Mathers and Loncar, 2006; Öberg et al., 2011). Tobacco use is the largest avoidable health risk in Europe, causing more problems than alcohol, drugs, and high blood pressure. The European Commission reports that every year 695,000 Europeans die prematurely of tobacco-related causes. The Center for Disease Control and Prevention (CDCP)'s Morbidity and mortality weekly report 2012 states that tobacco use continues to be the leading preventable cause of death and disease in the United States as well, with nearly 443,000 deaths occurring because of cigarette smoking and exposure to second-hand smoke. Furthermore, nearly $90 \%$ of adult smokers begin smoking by the age of eighteen (Physical Activity Advisory Committee, 2012; Ballard-Barbash et al., 2012). The Global adult tobacco survey fact sheet 2010, states that overall 301 million (28.1\%) of adults currently smoke in China: $52.9 \%$ of men and $2.4 \%$ of women; and among daily smokers in the category $20-34$ years old, $52.7 \%$ started smoking on a daily basis before the age of twenty. 
The Global adult tobacco survey 2012, in collaboration with the Turkish Statistical Institute, also indicates that 27\% of individuals aged 15 and over in Turkey currently smoke tobacco: $41.4 \%$ of men and $13.1 \%$ of women, and the percentage of current daily smokers is $23.8: 37.3 \%$ of men, $10.7 \%$ of women. Male smoking prevalence in Turkey is higher than in any Western European country, and is among the highest in Central Asia (Yürekli et al., 2010). One of the major results of the survey concerns the current smokers by age group, where $36.2 \%$ and $34.9 \%$ respectively of the individuals in the 35-44 and the 25-34 year age groups currently smoke. The survey also highlights that $18.9 \%$ of the 15-24 age group are current smokers: $31.2 \%$ of men and $6.8 \%$ of women. $37.2 \%$ of current smokers in the 15-24 age group have tried to quit smoking during the past 12 months; while only $28.1 \%$ are thinking about stopping within the next 12 months, and $49.9 \%$ of young adults are not interested in cessation. Even though tobacco smoking amongst young adults has declined as compared to 2008, it is still a significant public health problem in Turkey, and when analyzed by age group, cigarette smoking is the highest among younger adult populations (Turkish Statistical Institute, 2012; Yürekli et al., 2010).

The first anti-tobacco law in Turkey came into force in 1996, prohibiting smoking in the majority of public places. In 2004, Turkey became a party to the WHO Framework Convention for Tobacco Control. In accordance with the Convention, a tobacco control programme and action plan was prepared in 2007 with the participation of relevant people and institutions from both government and non-governmental organizations. The second anti-tobacco law was accepted on the 3rd January 2008, and expanded the number of smoke-free areas, with bans on smoking in hospitality-related work places, taxis, and open areas of schools. This law also bans sponsorship by tobacco companies. The main objective of the national tobacco control program and action plan was to ensure that by 2012, $80 \%$ of young people were non-smokers (Bilir et al, 2009). The share of cigarette and tobacco consumption decreased to $4.1 \%$ in 2011 , and if the comprehensive tobacco control legislation is effectively implemented, along with additional future tobacco control interventions, resulting in a significant reduction in prevalance, it is estimated that the number of adult Turkish smokers will fall to just over 8 million, and tobacco-attributable deaths will fall to just over 80,140 in 2050 (Yürekli et al., 2010; Turkish Statistical Institute, 2011).

Cigarette smoking carries well-known health risks such as morbidity, mortality, cancer, cardiovascular disease, and nicotine addiction (Hoffman et al., 2001). The death toll from smoking and smoking-related illness exceeds the combined tolls from AIDS, alcohol, cocaine, heroin, suicide, motor vehicle crashes, and fires (Moscal et al., 2010; Glynn et al, 1993). The fact that it does not have major psychotoxic effects, even when consumed in large amounts, has allowed cigarettes to become a socially acceptable drug (Herity et al., 1977). The use of substances, including cigarette smoking, which produce dependence usually begins during adolescence. However, the adverse health effects associated with them occur throughout life (Metintaş et al., 1998). Because of physiological dependence on nicotine, once adolescents start to smoke, it is very hard for them to quit, and they are more likely to develop a regular smoking pattern (Chassin et al., 1990; Stanton, 1995). While an adolescent's decision to experiment or to smoke regularly reflects an individual choice, it is shaped by their social environment, including his/her cultural environment, the smoking-related behaviors of family and peers, and social behavior related to smoking (Kaplan et al., 2001).

\section{A Brief Review of Literature}

In general, a number of factors are associated with youth tobacco use such as low socioeconomic status, use and approval of tobacco use by peers or siblings, exposure to smoking in movies, lack of skills to resist influences to tobacco use, smoking by parents or guardians, accessibility, availability, and the price of tobacco products, low levels of academic achievement, and so on (US Department of Health and Human Services, 1994 \& 2000). There are few environments where adults can be targeted as a whole for prevention and intervention, whereas the majority of children and adolescents can be reached at school and via other contexts (Towsend et al., 2006). The college years appear to be a time of increased risk for smoking initiation and movement into regular patterns of use, while college smokers are more likely to be non-daily smokers, meaning that they smoke more in social situations (Nichter et al., 2010). Recent studies indicate that individual personal factors, cognitive factors, and coping resources may play a key role in influencing which college students will have a propensity to initiate tobacco use and then continue to smoke (Von Ah et al., 2005). In addition, several demographic factors have been shown to be associated with college student smoking, such as gender, race, age, and college-educated parents (Reed et al., 2007).

There are numerous studies concerning cigarette smoking among adolescences, high school students and college students, in the literature. Many of these recent studies concentrated on the tobacco use of college students through similar or distinctive aspects, such as characteristics, patterns, contexts and consequences of smoking (Brandon and Baker, 1991; Waters et al., 2006; Berg et al., 2011; Cronk et al., 2011), factors of smoking initiation, smoking 
cessation, relapse prevention, and interventions (Emmons, et al., 1998; Lantz et al., 2000; Ramsay \& Hoffman; 2004; Murphy-Hoefer et al., 2005; Von Ah et al.; 2005), the relationships of demographic factors, other indicators and predictors on smoking behaviors (Patkar et al., 2003; Moran et al., 2004; Primack et al., 2008; Halperin et al., 2010), the accurate association between smoking and alcohol (Wechsler et al., 1997; Weitzman \& Chen, 2005; Dierker et al., 2006; Reed et al., 2007; Harrison et al., 2009), the prevalence of all forms of tobacco use, prevalence surveys involving comparative time period (Wechsler et al., 1998; Rigotti, et al. 2000; Rigotti, et al., 2005).

In Turkey, a large number of empirical studies have been carried out focusing on tobacco and/or cigarette smoking among adolescents, high school, and undergraduate students. Several recent studies concentrate on cigarette or tobacco use among undergraduate students in many different universities (Suner et al., 2009; Vatan et al., 2009), whereas a number of them pay attention to the prevalence of smoking and smoking habits and/or the corresponding associations with other substances (Dönmez et al., 2010; Çilingir et al., 2012). Otherwise; smoking patterns, smoking behavior, and related risk factors (Metintaş et al., 1998; Bahar, 2011; Bedir et al., 2011) have typically been studied by Turkish researchers.

\section{Methodology and Data Set}

Logit models express a qualitative dependent variable as a function of several independent variables, much in the manner of the general linear model (Fox, 1997). For a binary response variable $Y$ and an explanory variable $X$, let $\pi$ $(x)=P(Y=1 \mid X=x)=1-P(Y=0 \mid X=x)$. The odds ratio is a measure of association that has been widely used, as it approximates how much more likely (or unlikely) it is for the outcome to be present among those with $x=1$ than among those with $x=0$. The interpretation given for the odds ratio is based on the fact that in many instances it approximates a quantity called the relative risk, and this parameter is equal to the ratio $\pi(1) / \pi(0)$; and an odds ratio value below one means that the event is less likely to occur than not to occur (Hosmer \& Lemeshow, 2000; Pampel, 2000).

This paper employs to identify the demographic factors related to cigarette smoking of undergraduate students in Ataturk University, to interpret these factors and to assist in taking more effective precautions against cessation campaigns. For this purpose, a questionnaire was prepared and was applied to undergraduate students of every faculty. Using binary logistic regression analysis with cross-sectional data which was obtained by the questionnaire, it was suffered to identify factors affecting cigarette smoking. The data set being employed in this paper consists of cross-sectional data obtained using a questionnaire to determine the demographic factors related to cigarette smoking of undergraduate students in Atatürk University, Erzurum, in the northeast of Turkey. The nominal scaled dependent variable of the survey discriminates the case of current smokers $(Y=1)$ from non-smokers $(Y=0)$ through a yes-no question, that introduces the binary logit regression approach.

The aggregate number of students in Atatürk University during the period of the survey was 30,762 , and the survey requires 384 respondents. The corresponding survey performs a stratified sampling method in parallel with the number of students to keep the level of representation both proportional and as high as possible. Self-administrated questionnaires were distributed to 550 undergraduate students from 17 faculties, grouped into four categories: health sciences, social sciences, applied sciences and educational sciences. A total of 484 completed questionnaires were obtained in the survey. The percentage of questionnaire responses was $88 \%$, and the Cronbach's alpha coefficient value of the questionnaire was almost 0.71 , which suggests that the questionnaire has a high level of consistency and reliability (Kline, 1999; Cronbach, 1951).

The questionnaire utilized for the survey consisted of three sections. Section 1 comprised demographic indicators such as students' faculty, type of education, age, gender, where the student lived before their academic life, accommodation of students' parents, where the student lives currently, whether the parents are alive, professions of parents, number of individuals in the family, whether the student works, and whether the student receives a loan from the government. All these demographic factors are considered as the independent variables of the survey. Section 2 investigates the cigarette smoking of undergraduate students, such as the reason for starting smoking, the age when the student started smoking, which of their parents smoke, and who knows about the student's smoking habit. Section 3 comprises Likert scale questions on smoking and other relevant issues.

This paper concentrates on only demographic indicators of cigarette smoking. The survey analyzes the data set using the SPSS 17.0 computer package program, and utilizes the logistic regression approach to determine the demographic factors related to the cigarette smoking of undergraduate students. All of the factors included in this survey were interpreted as nominal and ordinal (thus categorical) variables. Non-categorical continuous data, such as age group, and the number of individuals, were labelled with numbers to obtain ordinal discrete variables. 


\section{Results}

As the descriptive statistics for demographic factors involved in the analysis of cigarette smoking indicate in Table 1, men $(79 \%)$ received higher scores than women $(21 \%)$ among current smokers. Most $(71.5 \%)$ of the undergraduate students were 19-22 years old, with primary-educated (nearly 72\%) students' and the dominancies (nearly $70 \%$ ) of freshmen and sophomores. In addition, most (nearly $76 \%$ ) of the participants were studying at the faculties of social and educational sciences, while more than half (nearly 56\%) of them were living in the East Anatolia and Black Sea Regions before their academic lives. Most (nearly 69\%) of the undergraduate students were living with their friends and parents, while most (nearly $83 \%$ ) of them were not working during their education. On the other hand, nearly all $(91.2 \%)$ of the participants' parents were alive; most ( $87 \%)$ of them were living in the provinces and districts; while more than half of them (54\%) were low-educated. Moreover, more than half (52\%) of their fathers were officers and workers, however most (nearly $86 \%$ ) of their mothers were not working, with most (66\%) of the participants had 4-6 people in their family. More than half (57\% and $52 \%$ ) of the participants were receiving education and tuition credits, while again more than half (58\%) of them were satisfied or very satisfied with their present lives.

Table 1. Descriptive Statistics for Current Smokers among Undergraduate Students

\begin{tabular}{|c|c|c|c|c|c|}
\hline Value Labels & Percentage & Value Labels & Percentage & Value Labels & Percentage \\
\hline Gender & & Present Residence & & Mother's Education & \\
\hline Male & 79.0 & with Friends & 35.3 & Primary School & 29.7 \\
\hline Female & 21.0 & with Parents & 33.8 & Secondary School & 20.3 \\
\hline Age Group & & Government Dormitory & 17.6 & High School & 18.8 \\
\hline $21-22$ & 40.1 & Private Dormitory & 8.1 & Literate & 15.2 \\
\hline $19-20$ & 31.4 & with Relatives & 2.9 & Non-literate & 10.1 \\
\hline 23 and higher & 25.5 & Alone & 2.2 & Graduate & 2.9 \\
\hline $17-18$ & 2.9 & Parents & & Undergraduate & 2.2 \\
\hline Type of Education & & Both of them are alive & 91.2 & Vocational College & 0.8 \\
\hline Primary & 72.3 & Only father is alive & 7.4 & Mother's Occupation & \\
\hline Secondary & 27.7 & Only mother is alive & 0.7 & Not working & 86.1 \\
\hline Year of Education & & Both of them are dead & 0.7 & Retired & 4.8 \\
\hline Freshman & 41.3 & Parent's Residence & & Officer & 4.2 \\
\hline Sophomore & 28.3 & Province & 56.5 & Self-employed & 3.0 \\
\hline Junior & 13.8 & District & 30.5 & Worker & 1.5 \\
\hline Senior & 13.8 & Village & 12.2 & Farmer & 0.3 \\
\hline Super Senior & 2.9 & County & 0.8 & Number of Family M & \\
\hline Faculty & & Father's Education & & 4-6 people & 65.7 \\
\hline Social Sciences & 43.8 & Primary School & 24.3 & 7-9 people & 13.4 \\
\hline Applied Sciences & 31.9 & High School & 23.5 & 1-3 people & 11.9 \\
\hline Health Sciences & 19.4 & Secondary School & 19.9 & 10 people and higher & 9.0 \\
\hline Educational Sciences & 4.9 & Undergraduate & 10.3 & Education Credit Rec & \\
\hline Region & & Vocational College & 10.3 & Yes & 57.0 \\
\hline East Anatolia & 39.1 & Graduate and higher & 5.1 & No & 43.0 \\
\hline Black Sea & 16.7 & Literate & 4.4 & Tuition Credit Receiv & \\
\hline Mediterranean & 10.1 & Non-literate & 2.2 & Yes & 51.9 \\
\hline Marmara & 9.4 & Father's Occupation & & No & 48.1 \\
\hline Southeast Anatolia & 8.7 & Officer & 32.8 & General Life Satisfac & \\
\hline Aegean & 8.0 & Worker & 19.0 & I am satisfied & 39.9 \\
\hline Central Anatolia & 8.0 & Retired & 17.5 & I am not all satisfied & 18.1 \\
\hline Occupation Status & & Self-employed & 14.6 & I am very satisfied & 16.7 \\
\hline Not Working & 83.1 & Craftsman & 9.5 & Neutral & 15.2 \\
\hline \multirow[t]{2}{*}{ Working } & 16.9 & Farmer & 5.8 & I am not satisfied & 10.1 \\
\hline & & Unemployed & 0.7 & & \\
\hline
\end{tabular}

This paper takes the maximum likelihood algorithm into consideration to analyze and estimate data by logistic regression. Before examining the logistic regression results the predicted percentage of the model was represented as $83 \%$ in Table 2 . The model was found to be statistically significant, $\chi^{2}(66,484)=183.027, p<.01$, with Nagelkerke $\mathrm{R}^{2}$ $=0.503$. 
Table 2. Predicted Percentage Correction and Omnibus Tests of Model Coefficient

\begin{tabular}{llcc}
\hline Observed & Predicted Percentage Correction & \\
\hline Step 1 & Do you smoke currently? & No & 91.4 \\
& & Yes & 62.0 \\
& Average percentage & & 83.0 \\
\hline Model & Chi-Square & Sig. \\
& (d.f. $=\mathbf{6 6}, \boldsymbol{N}=\mathbf{4 8 4})$ & \\
& 183.027 & 0.000 \\
-2 Log Likelihood & Nagelkerke $\mathbf{R}^{\mathbf{2}}$ & Sig. \\
324.043 & 0.503 & 0.000 \\
\hline
\end{tabular}

Table 3 exhibits the logistic regression output to determine demographic factors related to cigarette smoking of undergraduate students. In the table, the expression 'exponential (B)' refers to the odds ratio output of selected variables, which enables comparison between demographic factors with respect to the reference category. If the odds ratio is less than one, it is recommended to interpret the inverse of the observed value being obtained by taking the exponential of the odds ratio. In that case, the result would be interpreted as an opposite relationship. Reference categories and several variables were omitted from the model to avoid collinearity trap and only statistically significant results were presented in the corresponding table. As Table 3 indicates, demographic factors such as gender, geographical region, parents' residence, father's profession, the number of individuals in the family, professional status, and general satisfaction were found to be statistically significant, $p<.05$. In addition, faculty and present residence were found to be statistically significant, $p<.10$. Next, the odds ratios (referring to exponential (B) in the table) must be monitored in order to identify how these significant factors affected each other. For instance, when the odds ratios of the variable gender were examined, cigarette smoking prevalence in male students was found to be 5.556 times higher than in female students. Similarly, for geographical region the students lived in before their academic life, for several regions statistically significant results were obtained, including the Marmara Region, the Mediterranean, East Anatolia, the Aegean, and the Southeast Anatolia Regions. The probability of cigarette smoking in East Anatolian students was 14.458 times more likely to occur, while considering the Marmara Region as a reference category. Furthermore, the probabilities of cigarette smoking amongst respondents from the Aegean and Southeast Anatolia regions were also 4.260 and 4.610 times more likely to occur, respectively.

Table 3. Logistic Regression Output of Demographic Factors Related to Cigarette Smoking of Undergraduate Students

\begin{tabular}{lccclll}
\hline & B & S.E. & Wald & d.f. & Sig. & Exp(B) \\
\hline Faculty(3) & -1.678 & 0.990 & 2.874 & 1 & $0.090^{* * *}$ & 0.187 \\
\hline Gender(1) & 1.715 & 0.379 & 20.445 & 1 & $0.000^{*}$ & 5.556 \\
\hline Geographical region & & & 14.838 & 6 & $0.022^{* *}$ & \\
Geographical region(1) & 2.671 & 0.809 & 10.912 & 1 & $0.001^{*}$ & 14.458 \\
Geographical region(2) & 1.449 & 0.755 & 3.680 & 1 & $0.055^{* * *}$ & 4.260 \\
Geographical region(3) & 1.528 & 0.793 & 3.718 & 1 & $0.054^{* * *}$ & 4.610 \\
\hline Parents' residence & & & 10.138 & 3 & $0.017^{* *}$ \\
Present residence (5) & -2.785 & 1.607 & 3.002 & 1 & $0.083^{* * *}$ & 0.062 \\
\hline Father's profession & & & 14.458 & 6 & $0.025^{* *}$ \\
\hline The number of family members & & & 14.049 & 3 & $0.003^{*}$ \\
The number of family members(1) & -1.674 & 0.994 & 2.838 & 1 & $0.02^{* * *}$ & 0.187 \\
The number of family members(2) & -2.297 & 0.879 & 6.828 & 1 & $0.009^{*}$ & 0.101 \\
The number of family members(3) & -3.184 & 0.923 & 11.898 & 1 & $0.001^{*}$ & 0.041 \\
\hline Occupation status(1) & 2.219 & 0.631 & 12.371 & 1 & $0.000^{*}$ & 9.202 \\
\hline General satisfaction & & & 24.081 & 4 & $0.000^{*}$ & \\
General satisfaction(1) & 1.545 & 0.612 & 6.375 & 1 & $0.012^{* *}$ & 4.690 \\
\hline
\end{tabular}

${ }^{*} p<.01 * * p<.05 * * * p<.10$

When the probabilities of cigarette smoking were examined taking into account the parent's residence (for undergraduate students), respondents' parents living in a village setting was found to be statistically significant, $p<.05$. It is also important to note that the probability of cigarette smoking where the undergraduate student's father was unemployed was statistically significant, $p<.05$. Otherwise, the probabilities associated with the number of individuals in the students' family were also found to be statistically significant with respect to the reference category, for ten people and over. In this case, the probability of cigarette smoking relating to the 1-3 individuals per family 
category was 5.347 times less to occur. The same holds for the probabilities of cigarette smoking amongst families of 4-6 people and 7-9 people, which were 9.9 and 24.39 times less respectively than the probability associated with the $1-3$ people category.

Finally, the profession of undergraduate students was statistically significant, $p<.05$, while the probability of cigarette smoking amongst students who currently work was 9.202 times more than students who do not currently work. Furthermore, the probability of cigarette smoking by undergraduate students from the faculty of applied sciences was statistically significant, $p<.10$, and this probability was 5.347 less to occur. The probability of cigarette smoking in undergraduate students who were living alone was 16.129 times less than to occur.

The model was revised by taking only the statistically significant variables in Table 3 into consideration to determine the optimum model selection. The revised model was statistically significant, $p<.01, \chi^{2}(66,484)=144.534$, with the Nagelkerke $\mathrm{R}^{2}$ value equal to 0.391 . Because both the chi-square and $\mathrm{R}^{2}$ values were decreased with respect to the first model, the researchers selected the first model as the optimum combination of demographic factors.

\section{Conclusion \& Discussion}

Cigarette smoking is still the largest preventable health risk globally and in Turkey, causing more problems than any other drug, and has well-known health risks such as morbidity, mortality, cancer, cardiovascular disease, and nicotine addiction. Direct tobacco smoking is currently responsible for about five million deaths across the world each year (one death every six seconds), an additional six thousand people are estimated to die from the effects of second-hand smoke, while estimates suggest that by 2020 , seven of every ten people will be killed by tobacco-related diseases in the developing world. Adolescents, high school students, and college students are under threat from these risk factors, as nearly $90 \%$ of adult smokers begin smoking before the age of 18 . While an adolescent's decision to experiment or to smoke regularly reflects an individual choice, it is shaped by other demographic, social, environmental, and governmental factors.

Despite the fact that tobacco smoking amongst young adults has declined compared to 2008, it is still a significant public health problem in Turkey, and when analyzed by age group, cigarette smoking is the highest among younger adult populations. The second anti-tobacco law in 2008 expanded the number of smoke-free areas, with bans on smoking in hospitality-related work places, taxis, and open areas of schools. At present, $27 \%$ of individuals aged 15 and over in Turkey currently smoke tobacco; $41.4 \%$ of men and $13.1 \%$ of women and the percentage of current daily smokers is $23.8 ; 37.3 \%$ of men and $10.7 \%$ of women. Male smoking prevalence in Turkey is higher than in any Western European country and among the highest in Central Asia, while $18.9 \%$ of the $15-24$ year age group is current smokers; $31.2 \%$ of men and $6.8 \%$ of women. The share of cigarette and tobacco consumption decreased to $4.1 \%$ in 2011 and it is estimated that the number of tobacco-attributable deaths will fall to just over 80,140 in 2050 .

This paper implemented logistic regression analysis to obtain the results and to determine the demographic factors associated with cigarette smoking among undergraduate students in a rural university of Turkey. The results of the logistic regression analysis showed that the demographic factors of gender, geographical region, parents' residence, father's profession, family members, occupation status, general satisfaction, faculty and present residence had significant effects on the cigarette smoking of undergraduate students. Men were prone to cigarette smoking than women among current smokers, while undergraduate students generally negatively affected by their parents. Occupation status of undergraduate students might be related to economical status of them, when more healthy economical status might increase the risk of cigarette smoking addiction. General satisfaction of current smokers was surprisingly increased with cigarette smoking while the number of unsatisfied smokers was also remarkable. In this context, psychological factors might be discussed in-depth in the further researches. Moreover, environmental factors should be examined, upcoming studies may be concentrated on undergraduate students who are not living with their parents, and how they are affected by their place of residence, such as dormitories and attributes of their close friends. Consequenty, these multi-factor cross-sectional studies might be revised in the forthcoming years and the results might be discussed to illustrate the recent status of the problem along with the associated policies of Turkish government.

\section{References}

Bahar, H. H. (2011). Analysis of smoking status of potential teacher candidates according to various variables (sampling from Erzincan-Turkey). International Journal of Humanities and Social Science, 1(7), 89-99. [Online] Available: http://www.ijhssnet.com/journals/Vol._1_No._7_\%5bSpecial_Issue_June_2011\%5d/13.pdf 
Ballard-Barbash, R., Friedenreich C. M., Courneya K. S., Siddigi S. M., McTiernan A., \& Alfano C. M. (2012). Physical activity, biomarkers, and disease outcomes in cancer survivors: A systematic review. Journal of National Cancer Institute. 104, 815-840. http://dx.doi.org/10.1093/jnci/djs207

Bedir, S., Polat, D., \& Tural Dikmen, A. (2011). Factors affecting the cigarette use of Atatürk University Narman Vocation College students (trans. from Turkish). Atatürk University Journal of Economics and Administrative Sciences. 25(2), 237-248. [Online] Available: http://e-dergi.atauni.edu.tr/index.php/IIBD/article/view/6582

Berg, C. J., An, L. C., Thomas, J. L., Lust, K. A., Sanem, J. R., Swan, D. W., \& Ahluwalia, J. S. (2011). Smoking patterns, attitudes and motives: Unique characteristics among 2-year versus 4-year college students, Health Education Research. 26(4), 614-623. http://dx.doi.org/10.1093/her/cyr017

Bilir, N., Çakır, B., Dağlı, E., Ergüder, T., \& Önder, Z. (2009). Tobacco control in Turkey. World Health Organization Regional Office for Europe. [Online] Available: http://www.euro.who.int

Brandon, T. H., \& Baker, T. B. (1991). The smoking consequences questionnaire: The subjective expected utility of smoking in college students. Psychological Assessment: A Journal of Consulting and Clinical Psychology. 3, 484-491. http://dx.doi.org/10.1037/1040-3590.3.3.484

Center for Disease Control and Prevention (CDCP). (2010). Global adult tobacco survey fact sheet China: 2010. Atlanta, GA.

Center for Disease Control and Prevention (CDCP). (2012). Morbidity and mortality weekly report, 61(31), 582-604. Atlanta, GA.

Chassin, L., Presson, C. C., Sherman, S. J., \& Edwards, D. A. (1990). The natural history of cigarette smoking: Predicting young-adult smoking outcomes from adolescent smoking patterns. Health Psychology. 9(6), 701-716. http://dx.doi.org/10.1037/0278-6133.9.6.701

Cronbach, L. J. (1951). Coefficient alpha and the interval structure of tests. Psychometrika, 16(3), 297-334. [Online] Available: http://psych.colorado.edu/ carey/Courses/PSYC5112/Readings/alpha_Cronbach.pdf

Cronk, N. J., Harris, K. J., Harrar, S. W., Conway, K., Catley, D., \& Good, G. E. (2011). Analysis of smoking patterns and contexts among college student smokers. Substance Use \& Misuse, 46(8), 1015-1022. http://dx.doi.org/10.3109/10826084.2010.543746

Çilingir, D., Hintistan, S., \& Öztürk, H. (2012). Smoking habits and affecting factors of students of high school (trans. from Turkish). Gümüşhane University Journal of Health Sciences, 1(2), 70-85. [Online] Available: http://sbd.gumushane.edu.tr/media/uploads/sbd/articles/makale-3.pdf

Dierker, L., Lloyd-Richardson, E., Stolar, M., Flay, B., Tiffany, S., Collins, L., Bailey, S., Nichter, M., Nichter, M., Clayton, R., \& The Tobacco Etiology Research Network (2006). The proximal association between smoking and alcohol use among first year college students. Drug and Alcohol Dependence, 81(1), 1-9. http://dx.doi.org/10.1016/j.drugalcdep.2005.05.012

Dönmez, B., Çolak, H., \& Dönmez, K. H. (2010). Researching smoking, alcohol and drug addictions among high school students in Giresun (trans. from Turkish). Giresun University Journal of Karadeniz Social Sciences, 3, 35-42. [Online] Available: http://sbe.giresun.edu.tr

Emmons, K. M., Wechsler, H., Dowdall, G., \& Abraham, M. (1998). Predictors of smoking among US college students. American Journal of Public Health, 88(1), 104-107. http://dx.doi.org/10.2105/AJPH.88.1.104

European Commission Directorate for General Health. (2012). Attitudes of Europeans Towards Tobacco (European Commission Directorate for General Health Special Parameter report no.385). Brussels.

Fox, J. (1997). Applied regression analysis, linear models, and related methods. London: Sage Publications, Inc.

Glynn, T. J., Manley, M. W., Mills, S. L., \& Shopland, D. R. (1993). The United States Natural Cancer Institute and the science of tobacco control research. Cancer Detection and Prevention, 17, 507-512. [Online] Available: http://www.cancerprev.org/Journal/Issues/17/4/475

Halperin, A. C., Smith, S. S., Heiligenstein, E., Brown, D., \& Fleming, M. F. (2010). Cigarette smoking and associated health risks among students at five Universities. Nicotine \& Tobacco Research, 12(2), 96-104. http://dx.doi.org/10.1093/ntr/ntp182

Harrison, E. L. R., Hinson, R. E., \& McKee, S. A. (2009). Experimenting and daily smokers: Episodic patterns of alcohol and cigarette use. Addictive Behaviors, 34, 484-486. http://dx.doi.org/ 10.1016/j.addbeh.2008.12.013 
Herity, B. A., Horgan, J. M., Bourke, G. J., \& Wilson-Davies, K. (1977). Tobacco, alcohol and other drug use among medical students. Journal of the Irish Medical Association, 70(18), 532-539. [Online] Available: http://www.drugsandalcohol.ie/6504/1/319-0261.pdf

Hoffman, J. H., Welte, J. W., \& Barnes, G. M. (2001). Co-occurence of alcohol and cigarette use among adolescents. Addictive Behaviors, 26(1), 63-78. http://dx.doi.org/10.1016/S0306-4603(00)00089-7

Hosmer, D. W., \& Lemeshow, S. (2000). Applied logistic regression. New York: John Wiley \& Sons, Inc.

Kaplan, C. P., Nápoles-Springer, A., Stewart, S. L., \& Pérez-Stable, E. J. (2001). Smoking acquisition among adolescents and young Latinas: The role of socioenvironmental and personal factors. Addictive Behaviors, 26(4), 531-550. http://dx.doi.org/10.1016/S0306-4603(00)00143-X

Kline, P. (1993). The handbook of psychological testing. London: Routledge.

Lantz, P. M., Jacobson, P. D., Warner, K. E., Wasserman, J., Pollack, H. A., Berson, J., \& Ahlstrom, A. (2000). Investing in youth tobacco control: A review of smoking prevention and control strategies. Tobacco Control, 9 , 47-63. http://dx.doi.org/10.1136/tc.9.1.47

Mathers, C. D., \& Loncar, D. (2006). Projections of global mortality and burden disease from 2002 to 2030. PLoS Medicine, 3(11): e442. [Online] Available: http://www.plosmedicine.org

Maziak, W., Eissenberg, T., Klesges, R. C., Keil, U., \& Ward, K. D. (2004). Adapting smoking cessation interventions for developing countries: A model for the Middle East. International Journal of Tuberculosis and Lung Disease, 8(4), 403-413. [Online] Available: http://docstore.ingenta.com/

Menard, S. (2002). Applied logistic regression analysis, London: Sage Publications, Inc.

Metintaş, S., Sariboyaci, M. A., Nuhoğlu, S., Metintaş, M., Kalyoncu, C., Etiz, S., Özdemir, N., \& Aktaş, C. (1998). Smoking patterns of university students in Eskişehir, Turkey. Public Health, 112(4), 261-264. http://dx.doi.org/10.1038/sj.ph.1900470

Moran, S., Wechsler, H., \& Rigotti, N. A. (2004). Social smoking among US college students. Pediatrics, 114(4), 1028-1034. http://dx.doi.org/10.1542/peds.2003-0558-L

Murphy-Hoefer, R., Griffith, R., Pederson, L. L., Crosett, L., Iyer, S. R., \& Hiller, M. D. (2005). A review of interventions to reduce tobacco use in colleges and universities. American Journal of Preventive Medicine, 28(2), 188-200. http://dx.doi.org/10.1016/j.ampere.2004.10.015

Nichter, M., Nichter, M., Carkoglu, A., Lloyd-Richardson, E., \& the Tobacco Etiology Research Network. (2010). Smoking and drinking among college students: "It's a Package Deal.". Drug and Alcohol Dependence, 106(1), 16-20. http://dx.doi.org/10.1016/j.drugalcdep.2009.07.025

Öberg, M., Jaakkola Maritta, S., Woodward, A., Peruga A., \& Prüss-Üstün A. (2011). Worldwide burden of disease from exposure to second-hand smoke: A retrospective analysis of data from 192 countries. The Lancet, 377(9760), 139-146. http://dx.doi.org/10.1016/S0140-6736(10)61388-8

Pampel, F. C. (2000). Logistic regression: A primer. California: Sage Publications, Inc.

Patkar, A. A., Hill, K., Batra, V., Vergare, M. J., \& Leone, F. T. (2003). A comparison of smoking habits among medical and nursing students. Chest Journal, 124(4), 1415-1420. [Online] Available: http://dev.chestjournal.chestpubs.org/data/Journals/CHEST/20384/1415.pdf

Physical Activity Guidelines Advisory Committee. (2012). Physical activity guidelines advisory committee report, 2008. Washington DC: US Department of Health and Human Services.

Primack, B. A., Sidani, J., Agarwal, A. A., Shadel, W. G., Donny, E. C., \& Eissenberg, T. E. (2008). Prevalence of and associations with waterpipe tobacco smoking among U.S. university students, Annals of Behavioral Medicine. 36, 81-86. http://dx.doi.org/10.1007/s12160-008-9047-6

Ramsay, J., \& Hoffmann A. (2004). Smoking cessatition and relapse prevention among undergraduate students: A pilot demonstration project. Journal of American College Health, 53(1), 11-18. http://dx.doi.org/10.3200/JACH.53.1.11-18

Reed, M. B., Wang, R., Shillington, A. M., Clapp, J. D., \& Lange, J. E. (2007). The relationship between alcohol use and cigarette smoking in a sample of undergraduate college students. Addictive Behaviors, 32, 449-464. ttp://dx.doi.org/10.1016/j.addbeh.2006.05.016

Rigotti, N. A., Lee, J. E., \& Wechsler, H. (2000). US college students' use of tobacco products. The Journal of the Americal Medicine Association, 284(6), 699-705. http://dx.doi.org/10.1001/jama.284.6.699. 
Rigotti, N. A., Moran, S. E., and Wechsler, H. (2005). US college students' exposure to tobacco promotions: prevalence and association with tobacco use, American Journal of Public Health. 95(1), 138-144. http://dx.doi.org/10.2105/AJPH.2003.026054

Schorling, J. B., Gutgesell, M., Klas, P., Smith, D., \& Keller, A. (1994). Tobacco, alcohol and drug use among college students. Journal of Substance Abuse, 6(1), 105-115. http://dx.doi.org/10.1016/S0899-3289(94)90143-0

Stanton, W. R. (1995). DSM-III-R Tobacco dependence and quitting during late adolescence. Addictive Behaviors, 20(5), 595-603. http://dx.doi.org/10.1016/0306-4603(95)00019-9

Suner, A., Firuzan, A. R., \& Ayvaz, Y. Y. (2009). An application about the university students in İzmir with stratified cluster sampling (trans. from Turkish). Süleyman Demirel University Journal of Faculty of Economics and Administrative Sciences, 14(1), 407-424. [Online] Available: http://sablon.sdu.edu.tr

The World Bank. (1999). Curbing the epidemic: Governments and the economics of tobacco control. Washington DC.

Towsend, L., Flisher, A. J., Gilreath, T., \& King G. (2006). A systematic literature review of tobacco use among adults 15 years and older in Sub-Saharan Africa. Drug and Alcohol Dependence, 84(1), 14-27. http://dx.doi.org/10.106/j.drugalcdep.2005.12.008

Turkish Statistical Institute (TSI). (2012). Global Adult Tobacco Survey Bulletin. (Turkish Statistical Institute report no. 13142). Ankara.

Turkish Statistical Institute (TSI). (2012). Household Consumption Expenditure Survey Bulletin, 2011. (Turkish Statistical Institute report no. 10875). Ankara.

U.S. Department of Health and Human Services. (1994). Preventing tobacco use among young people: A report of the Surgeon General. Atlanta: U.S. Department of Health and Human Services, Centers for Disease Control and Prevention, Office on Smoking and Health.

U.S. Department of Health and Human Services. (2000). Preventing tobacco use among young people: A report of the Surgeon General. Atlanta: U.S. Department of Health and Human Services, Centers for Disease Control and Prevention, National Center for Chronic Disease Prevention and Health Promotion, Office on Smoking and Health.

Vatan, I., Ocakoğlu, H., \& Irgil, E. (2009). Determining smoking prevalence in the Uludag University Faculty of Medicine (trans. from Turkish). TAF Preventive Medical Bulletin, 8(1), 43-48. [Online] Available: http://www.scopemed.org/fulltextpdf.php? $\mathrm{mno}=456$

Von Ah, D., Ebert, S., Ngamvitroj, A., Park, N., \& Kang, D. (2005). Factors related to cigarette smoking initiation and use among college students. Tobacco Induced Diseases, 3(1), 27-40. http://dx.doi.org/10.1186/1617-9625-3-5

Waters, K., Harris, K., Hall, S., Nazir, N., \& Waigant, A. (2006). Characteristics of social smoking among college students. Journal of American College Health, 55(3), 133-139. http://dx.doi.org/10.3200/JACH.55.3.133-139

Wechsler, H., Davenport, A. E., Dowdall, G. W., Grossman, S. J., \& Zanakos, S. (1997). Binge drinking, tobacco, and illicit drug use and involvement in college athletics. Journal of American College Health, 45(5), 195-200. http://dx.doi.org/10.1080/07448481.1997.9936884

Wechsler, H., Rigotti, N. A., Gledhill-Hoyt, J., Lee H. (1998). Increased levels of cigarette use among college students, The Journal of the American Medicine Association. 280(19), 1673-1678. http://dx.doi.org/10.1001/jama.280.19.1673

Wechsler, H. Lee, J. F., \& Rigotti, N. A. (2001). Cigarette use by college students in smoke-free housing. American Journal of Preventive Medicine, 20(3), 202-207. http://dx.doi.org/10.1016/S0749-3797(00)00313-5

Weitzman, E. R., \& Chen, Y. (2005). The co-occurrence of smoking and drinking among young adults in college: National survey results from the United States. Drug and Alcohol Dependence. 80(3), 377-386. http://dx.doi.org/10.1016/j.drugalcdep.2005.05.008

World Health Organization. (2011). Global Status Report on Noncommunicable Diseases 2010. Geneva.

World Health Organization. (2012). WHO Global Report on Mortality Attributable to Tobacco. Geneva.

Yürekli, A., Önder, Z., Elibol, M., Erk, N., Çabuk A., Fisunoğlu M., Erk, S. F., \& Chaloupka, F. J. (2010). The economics of tobacco and tobacco taxation in Turkey. Paris: International Union against Tuberculosis and Lung Disease. 